\title{
CORRIGENDUM
}

\section{Between order and chaos}

James P. Crutchfield

Nature Phys. 8, 17-24 (2012); published online 22 December 2011; corrected online 17 May 2013.

In the version of this Review Article originally published online there were several errors. In the section entitled 'Complicated yes, but is it complex?', seventh paragraph, the subscripts should appear as follows: past $X_{: t ;}$; future $X_{t ;}$; and blocks $\mathrm{X}_{t: t}$. All instances of $x_{: l}$ should appear as $x_{0: l}$. In the section entitled 'Applications', in the third and seventh paragraphs, $x_{\text {: }}$ should appear as $x_{0:}$. In the caption of Fig. $1 \mathrm{~d}$, the distributions should be listed as $\operatorname{Pr}(\mathrm{A}, \mathrm{B}, \mathrm{C}, \mathrm{D})$, and panel $\mathbf{d}$ should have been attributed to ref. 45 . These errors have now been corrected in the PDF and HTML versions of the Review Article. 